\title{
Influence of Expansion of Extracellular Volume on Tubular Reabsorption of Sodium Independent of Changes in Glomerular Filtration Rate and Aldosterone Activity *
}

\author{
Floyd C. Rector, Jr., George Van Giesen, $\dagger$ Fredrik KiIL, † and \\ Donald W. Seldin \\ (From the Department of Internal Medicine, the University of Texas Southwestern Medical \\ School, Dallas, Texas)
}

The excretion of sodium by the kidney is influenced by changes in glomerular filtration rate (GFR), serum sodium concentration, adrenocortical activity, the quantity of nonreabsorbable solutes in the glomerular filtrate, and the volume of extracellular fluid (ECF) $(1-4)$. Some of these factors alter sodium excretion by affecting the amount of sodium filtered; others modulate the tubular reabsorption of sodium.

The mechanism whereby acute changes in the volume of ECF influence sodium excretion is not entirely clear. At least two factors, however, have been identified. Both the secretory rate of aldosterone and the GFR are influenced by alteration in the volume of ECF and may play important roles in the regulation of sodium excretion by volume. Alteration of sodium excretion by patients with Addison's disease in a parallel fashion with sodium intake and without detectable changes in $\operatorname{GFR}(5,6)$ suggests that a third factor may be operative. Furthermore, a number of investigators (7-9) have shown that, under conditions where the volume of ECF was acutely altered in the face of fixed adrenocortical activity, sodium excretion varied independently of GFR, suggesting that changes in volume were in some manner influencing the tubular reabsorption of sodium independent of adrenocortical hormones.

* Submitted for publication August 7, 1963; accepted October 31, 1963.

This work was supported in part by U. S. Public Health Service grants HTS-5469 and 2A-5038.

$\doteqdot$ Postdoctoral fellow under U. S. Public Health Service training grant 2A-5028. Present address: Department of Internal Medicine, Medical College of Georgia, Augusta, Ga.

$\ddagger$ Present address: Institute for Experimental Medical Research, Ullevaal Hospital, Oslo, Norway.
All these studies, however, are open to the objection that errors in the measurements of GFR could lead to erroneous conclusions concerning the relative roles of filtration and tubular reabsorption $(1,10)$.

Recently, de Wardener, Mills, Clapham, and Hayter (11) circumvented this difficulty by demonstrating that acute expansion of ECF volume with an infusion of isotonic saline increased sodium excretion despite both the administration of large doses of $9 \boldsymbol{\alpha}$-fluorohydrocortisone and marked reductions in GFR produced by aortic constriction. These results, which have subsequently been confirmed and extended by Levinsky and Lalone (12), establish that the increased sodium excretion after expansion of the ECF volume is the consequence of diminished tubular reabsorption of sodium via some mechanism other than suppression of adrenocortical activity. They do not, however, define the locus in the nephron wherein sodium reabsorption must have been suppressed.

Our experiments were designed to localize within the nephron the site at which changes in ECF volume regulate sodium reabsorption. This we achieved by demonstrating that massive inf $u$ sions of hypotonic saline increase sodium excretion under the following circumstances: 1) marked reduction in GFR produced by constriction of the aorta, 2) constant and maximal aldosterone activity achieved by injections of the hormone, and 3) maximal water diuresis. Under these conditions of maximal suppression of antidiuretic hormone ( $\mathrm{ADH})$, the amount of filtrate delivered to the diluting segment of the nephron can be roughly approximated from the urine volume, and the quantity of sodium reab- 
sorbed in this area can be estimated from the clearance of solute-free water $\left(\mathrm{C}_{\mathrm{H}_{2} \mathrm{O}}\right)$ and the excretion of potassium.

We discovered that the infusion of hypotonic saline increases not only the excretion of sodium but also urine flow, the $\mathrm{C}_{\mathrm{H}_{2} \mathrm{O}}$, and the excretion of potassium. The increased urine flow, under the conditions of our experiments, indicates augmented delivery of filtrate to the distal nephron; the increased $\mathrm{C}_{\mathrm{H}_{2} \mathrm{O}}$ and potassium excretion are evidence for enhanced sodium reabsorption in this area. From these results we conclude that expansion of ECF volume sharply depresses the reabsorption of sodium in the more proximal portions of the nephron. ${ }^{1}$ The increment delivered to the distal nephron is partially reabsorbed, thereby enhancing $\mathrm{C}_{\mathrm{H}_{2} \mathrm{O}}$ and potassium excretion, and partially excreted into the urine.

\section{Methods}

Female mongrel dogs, weighing 10 to $20 \mathrm{~kg}$ and fed regular commercial diets, were anesthetized with sodium pentobarbital. To 4 dogs $500 \mu \mathrm{g}$ of $d$-aldosterone

1 In the following discussion the term "distal portion of the nephron" is used to denote those areas that are relatively water impermeable in the absence of $\mathrm{ADH}$. The term "proximal portion of the nephron" is used to denote those segments proximal to the water-impermeable areas; these include the proximal convoluted tubule, the pars recta, and the thin limb of the loop of Henle. per $\mathrm{kg}$ body weight was given intravenously 2 hours before the study was begun; to $2 \operatorname{dogs}$ no aldosterone was given.

The dogs were prepared by exposing the aorta through a left flank incision and then placing a specially designed screw clamp around the aorta above both renal arteries. The clamp extended to the outside so that adjustments in the degree of aortic constriction could be made after the flank incision was closed. Femoral arterial pressure was measured through a catheter connected to a mercury manometer.

After the clamp was positioned around the aorta, water diuresis was established by administering $2 \%$ glucose at rates of 4 to $7 \mathrm{ml}$ per minute; when urine flow stabilized at about 3 to $6 \mathrm{ml}$ per minute, 3 or 4 collection periods were obtained. Then $0.45 \%$ saline was administered at rates of 25 to $35 \mathrm{ml}$ per minute. Finally, 15 to 20 minutes after the beginning of the saline infusion, the aorta was constricted by the clamp so that pressure in the femoral artery was reduced to approximately $50 \%$ of control values (simultaneously the saline infusion was reduced to 10 to $12 \mathrm{ml}$ per minute), and 3 to 6 collection periods were obtained.

Inulin was infused throughout the experiment at the rate of $10 \mathrm{mg}$ per minute after a priming dose of $1 \mathrm{~g}$. At the mid-point of each collection period, blood samples were drawn through a Cournand needle in the femoral artery. Urine samples were collected through an indwelling bladder catheter.

Inulin was analyzed by the method of Walser, Davidson, and Orloff (13). Serum and urine sodium and potassium were determined on an internal standard flame photometer. Plasma and urine osmolality were measured on the Fiske osmometer. Standard deviation of the mean was calculated according to Snedecor (14).

TABLE I

Effects of hypotonic saline infusion and aortic constriction on water and electrolyte excretion in a $\operatorname{dog}(U)$ given aldosterone*

\begin{tabular}{|c|c|c|c|c|c|c|c|c|c|c|}
\hline Time & Serum Na & GFR & $\mathrm{CH}_{2} \mathrm{O}$ & Uflow & $U_{\mathrm{Na}}$ & $\tau_{\mathrm{NaV}}$ & L'K & $\mathrm{UKV}_{\mathbf{K}}$ & Uosm & $\mathrm{C}_{\mathrm{o} \times \mathrm{m}}$ \\
\hline $\min$ & $m E q / L$ & $m l / m i n$ & $m l / m i n$ & $m l / \min$ & $m E q / L$ & $\mu E q / m i n$ & $m E \mathbf{Q} / L$ & $\mu E q / \min$ & $m O s m / L$ & $m l / m i n$ \\
\hline-120 & \multicolumn{10}{|c|}{$500 \mu \mathrm{g} / \mathrm{kg}$ body weight iv $d$-aldosterone } \\
\hline 0 & \multicolumn{10}{|c|}{ Start $2 \%$ glucose at $6 \mathrm{ml} / \mathrm{min}$} \\
\hline $\begin{array}{l}110-120 \\
120-130 \\
130-140 \\
140-150\end{array}$ & $\begin{array}{l}132.0 \\
130.4 \\
130.9 \\
131.3\end{array}$ & $\begin{array}{l}89 \\
88 \\
73 \\
73\end{array}$ & $\begin{array}{l}1.1 \\
2.0 \\
2.5 \\
2.5\end{array}$ & $\begin{array}{l}2.2 \\
3.0 \\
3.3 \\
3.2\end{array}$ & $\begin{array}{l}1.7 \\
1.7 \\
1.6 \\
1.6\end{array}$ & $\begin{array}{l}3.7 \\
5.1 \\
5.3 \\
5.2\end{array}$ & $\begin{array}{r}12.9 \\
9.7 \\
7.1 \\
7.0\end{array}$ & $\begin{array}{l}28.4 \\
29.1 \\
23.4 \\
22.6\end{array}$ & $\begin{array}{r}127 \\
83 \\
66 \\
63\end{array}$ & $\begin{array}{l}1.1 \\
1.0 \\
0.8 \\
0.8\end{array}$ \\
\hline & \multicolumn{10}{|c|}{ Discontinue glucose infusion } \\
\hline 151 & \multicolumn{10}{|c|}{ Start $0.45 \%$ saline at $30 \mathrm{ml} / \mathrm{min}$} \\
\hline 159 & \multicolumn{10}{|c|}{ Constrict aorta } \\
\hline $\begin{array}{l}160-165 \\
165-173 \\
173-179 \\
179-185 \\
185-193\end{array}$ & $\begin{array}{l}129.5 \\
128.4 \\
131.6\end{array}$ & $\begin{array}{l}64 \\
63 \\
59 \\
68 \\
57\end{array}$ & $\begin{array}{l}3.9 \\
2.8 \\
3.3 \\
3.1 \\
2.7\end{array}$ & $\begin{array}{l}4.6 \\
3.5 \\
4.1 \\
4.1 \\
3.6\end{array}$ & $\begin{array}{l}2.9 \\
4.1 \\
5.4 \\
6.1 \\
6.9\end{array}$ & $\begin{array}{l}13.3 \\
14.2 \\
22.4 \\
24.8 \\
24.7\end{array}$ & $\begin{array}{r}5.9 \\
8.8 \\
9.9 \\
11.0 \\
12.4\end{array}$ & $\begin{array}{l}27.0 \\
30.5 \\
41.0 \\
44.7 \\
44.4\end{array}$ & $\begin{array}{l}41 \\
52 \\
52 \\
64 \\
64\end{array}$ & $\begin{array}{l}0.7 \\
0.7 \\
0.8 \\
1.0 \\
0.9\end{array}$ \\
\hline
\end{tabular}

${ }^{*} \mathrm{GFR}=$ glomerular filtration rate, $\mathrm{C}_{\mathrm{H}_{2} \mathrm{O}}=$ clearance of solute-free water, $\mathrm{U}=$ urine, $\mathrm{U}_{\mathrm{Na}} \mathrm{V}=$ rate of urine sodium excretion, $\mathrm{U}_{\mathrm{osm}}=$ urine osmolality, and $\mathrm{C}_{\mathrm{osm}}=$ osmolar clearance. 
TABLE II

Effects of hypotonic saline infusion and aortic constriction on water and electrolyte excretion*

\begin{tabular}{|c|c|c|c|c|c|c|c|c|c|c|}
\hline Dog & Period & Serum Na & GFR & Filtered Na & $U_{\text {flow }}$ & $\mathrm{U}_{\text {osm }}$ & $\mathrm{UNa}_{\mathrm{Na}}$ & $\mathrm{U}_{\mathbf{K}} \mathrm{V}$ & $\mathrm{CH}_{2} \mathrm{O}$ & $\begin{array}{l}\text { Filtrate } \\
\text { reabsorbed } \dagger\end{array}$ \\
\hline \multirow{4}{*}{$P^{\prime}$} & & $m E q / L$ & $m l / m i n$ & $\mu E q / \min$ & $m l / m i n$ & $m O s m / L$ & $\mu E q / \min$ & $\mu E q / m \imath n$ & $m l / \min$ & $\%$ \\
\hline & Water & 135 & 77 & 10,395 & 5.5 & 43 & 4 & 41 & 4.6 & 92.8 \\
\hline & & 133 & 63 & 8,349 & 6.4 & 30 & 13 & 52 & 5.7 & 89.8 \\
\hline & $\%$ change & -1 & -18 & -20 & +16 & -30 & +225 & +27 & +24 & -3.0 \\
\hline \multirow{3}{*}{$\mathrm{U}$} & Water & 134 & 91 & 12,194 & 3.0 & 89 & 4 & 39 & 2.0 & 96.7 \\
\hline & Saline plus & 134 & 64 & 8,576 & 3.1 & 59 & 13 & 27 & 2.5 & 95.1 \\
\hline & $\begin{array}{l}\text { striction } \\
\% \text { change }\end{array}$ & 0 & -30 & -30 & +3 & -34 & +225 & -31 & +25 & -1.6 \\
\hline \multirow{3}{*}{$\mathrm{S}$} & IVater & 131 & 81 & 10,611 & 2.9 & 85 & 5 & 26 & 2.0 & 96.4 \\
\hline & $\begin{array}{l}\text { Saline plus } \\
\text { aortic con- }\end{array}$ & 130 & 62 & 8,060 & 4.0 & 55 & 20 & 38 & 3.2 & 93.5 \\
\hline & $\%$ change & -1 & -23 & -24 & +38 & -35 & +300 & +46 & +60 & -2.9 \\
\hline \multirow{3}{*}{$\mathrm{I}$} & Water & 140 & 91 & 12,740 & 4.4 & 81 & 9 & 36 & 3.1 & 95.2 \\
\hline & $\begin{array}{l}\text { Saline plus } \\
\text { aortic con- }\end{array}$ & 138 & 79 & 10,902 & 5.4 & 53 & 24 & 49 & 4.4 & 93.2 \\
\hline & $\%$ change & -1 & -13 & -14 & +23 & -34 & +167 & +36 & +42 & -2.0 \\
\hline \multirow{3}{*}{$10+$} & Water & 134 & 84 & 11,250 & 5.9 & 123 & 30 & 20 & 3.6 & 93.0 \\
\hline & $\begin{array}{l}\text { Saline plus } \\
\text { aortic con- }\end{array}$ & 131 & 68 & 8,910 & 7.7 & 74 & 57 & 37 & 5.7 & 88.7 \\
\hline & $\%$ change & -2 & -19 & -21 & +31 & -40 & +90 & +85 & +58 & -4.3 \\
\hline \multirow{6}{*}{$11 \ddagger$} & $\begin{array}{l}\text { Water } \\
\text { Saline plus }\end{array}$ & $\begin{array}{l}130 \\
127\end{array}$ & $\begin{array}{l}80 \\
56\end{array}$ & $\begin{array}{r}10,400 \\
7,112\end{array}$ & $\begin{array}{l}6.3 \\
7.0\end{array}$ & $\begin{array}{l}91 \\
83\end{array}$ & $\begin{array}{l}24 \\
59\end{array}$ & $\begin{array}{l}22 \\
38\end{array}$ & $\begin{array}{l}4.3 \\
5.1\end{array}$ & $\begin{array}{l}92.1 \\
87.5\end{array}$ \\
\hline & aortic con- & & & & & & & & & \\
\hline & $\%$ change & -2 & -30 & -32 & +11 & -9 & +146 & +73 & +18 & -4.6 \\
\hline & Mean $\%$ of & -1.2 & -22 & -24 & +20 & -30 & +192 & +39 & +38 & -3.1 \\
\hline & SD & \pm 0.2 & \pm 6.9 & \pm 6.6 & \pm 14.1 & \pm 10.9 & \pm 76 & \pm 35.8 & \pm 19.7 & \pm 2.3 \\
\hline & $\mathrm{p}$ & $<0.001$ & $<0.001$ & $<0.001$ & $<0.025$ & $<0.005$ & $<0.001$ & $<0.050$ & $<0.010$ & $<0.025$ \\
\hline
\end{tabular}

* See footnote to Table I for explanation of abbreviations.

$\dagger$ Calculated by the expression $\left(\mathrm{GFR}-\frac{\text { urine flow }}{\mathrm{GFR}}\right) 100$.

$\ddagger$ Dogs not given $d$-aldosterone.

\section{Results}

The protocol of a representative experiment in which aldosterone was given is presented in Table I. The results of all experiments are summarized in Table II. Water diuresis was established in each dog as evidenced by the low urine osmolality. The urinary excretion of sodium in the dogs given aldosterone was very low, ranging from 4 to $9 \mu \mathrm{Eq}$ per minute, whereas in the dogs not given aldosterone it was much higher, ranging from 24 to $30 \mu \mathrm{Eq}$ per minute. When the aorta was constricted during the infusion of hypotonic saline, GFR was reduced by approximately $22 \%$, and the plasma concentration of sodium remained constant or fell slightly; consequently there was a sharp reduction in the filtered load of sodium. In spite of this, the infusion of saline resulted in significant increases in urine flow, $\mathrm{C}_{\mathrm{H}_{2} \mathrm{O}}$, and the excretion of sodium and potassium. Since urine flow increased in the face of a reduced GFR, the percentage of glomerular filtrate reabsorbed by the tubule [GFR - (urine flow/GFR)] $\times 100$, was reduced (last column, Table II) in each experiment; the mean reduction for all experiments was $3 \%$. 
TABLE JII

Effects of hypotonic saline infusion on water and solute excretion before and during aortic constriction*

\begin{tabular}{|c|c|c|c|c|c|c|}
\hline Dog S & GFR & $\mathrm{U}_{\text {flow }}$ & Losm & $\mathrm{U}_{\mathrm{Na}}$ & $\mathrm{CH}_{2} \mathrm{O}$ & $C_{o s m}$ \\
\hline & $\mathrm{ml} / \mathrm{min}$ & $\mathrm{ml} / \mathrm{min}$ & $m O s m / L$ & $m E q / L$ & $m l / m i n$ & ml/min \\
\hline Water diuresis, normal GFR & 81 & 2.9 & 85 & 1.7 & 2.0 & 0.9 \\
\hline Hypotonic saline diuresis before aortic constriction & 85 & 10.3 & 87 & 32.5 & 7.0 & 3.3 \\
\hline Hypotonic saline diuresis during aortic constriction & 62 & 4.0 & 55 & 5.0 & 3.2 & 0.8 \\
\hline
\end{tabular}

* See footnote to Table I for explanation of abbreviations.

The relatively low rates of urine flow during the periods of water diuresis suggest the possibility that endogenous ADH might not have been completely suppressed and that the observed fall in urine osmolality and increments in urine flow and $\mathrm{C}_{\mathrm{H}_{2} \mathrm{O}}$ during saline diuresis were the consequence of further suppression of $\mathrm{ADH}$ by volume expansion. Despite the low urine flows in some of the studies, the urine osmolalities were sufficiently low to suggest virtual absence of $\mathrm{ADH}$ (e.g., Table I, $\operatorname{dog}$ U, 63 mOsm per L; Table II, $\operatorname{dog}$ P, $43 \mathrm{mOsm}$ per L). The low urine flows were probably the consequence of the low rate of sodium excretion, which in turn was the result of the large doses of aldosterone; both urine flow and sodium excretion were lower in the two dogs given aldosterone than in those not receiving aldosterone.

Further evidence that the changes noted during saline diuresis plus aortic constriction were not the consequence of further suppression of endogenous $\mathrm{ADH}$ by volume expansion is indicated by the data presented in Table III, which is representative of four studies in which periods were obtained during hypotonic saline infusion but before aortic constriction. In these experiments, urine osmolality was permitted to stabilize at a minimal value during water diuresis alone; then hypotonic saline was infused for $1 \frac{1}{2}$ hours. The infusion of saline, although increasing osmolar clearance $\left(\mathrm{C}_{\mathrm{osm}}\right)$ and $\mathrm{C}_{\mathrm{H}_{2} \mathrm{O}}$, did not alter the urine osmolality. However, when GFR was then acutely reduced by aortic constriction, urine osmolality promptly fell. The lower urine osmolality observed during saline diuresis plus aortic constriction was, therefore, not the result of further depression of $\mathrm{ADH}$ by volume expansion but rather the direct consequence of aortic constriction. The possibility that aortic constriction might inhibit endogenous $\mathrm{ADH}$ is very unlikely, first because aortic constriction during water diu- resis alone causes a rise, not a further fall, in urine osmolality (15) and, second, recent studies in our laboratory (16) have shown that constriction of one renal artery during saline diuresis causes a unilateral drop in osmolality without a change on the control side. Thus, there is no evidence that the fall in urine osmolality during hypotonic saline infusion plus aortic constriction was the consequence of further suppression of $\mathrm{ADH}$ either by volume expansion or by aortic constriction.

The pattern of water and solute excretion after aortic constriction differed from that during infusions of hypotonic saline alone. When compared to water diuresis, hypotonic saline resulted in a marked and proportionate rise in both $\mathrm{C}_{\text {osin }}$ and $\mathrm{C}_{\mathrm{H}_{2} \mathrm{O}}$ (Table III). In contrast, after aortic constriction, $\mathrm{C}_{\mathrm{H}_{2} \mathrm{O}}$ was increased, but $\mathrm{C}_{\mathrm{osm}}$ was the same as in water diuresis. ${ }^{2}$ These results suggest that aortic constriction during saline diuresis, by slowing tubular flow, permits augmented sodium reabsorption per unit of tubular fluid in the water-impermeable segments of the nephron, resulting in a fall in urine osmolality as well as a rise in $\mathrm{C}_{\mathrm{H}_{2} \mathrm{O}}$.

\section{Discussion}

De Wardener and co-workers (11) and Levinsky and Lalone (12) clearly demonstrated that acute expansion of the ECF volume with isotonic saline can increase sodium excretion even though the filtered load of sodium is decreased. These results, which are confirmed by our experiments. might be explained in one of several ways. The

2 As indicated in Table II, sodium excretion increased during hypotonic saline diuresis plus aortic constriction when compared to the findings during water diuresis alone. The failure of $\mathrm{C}_{\text {osm }}$ to rise in the face of increased urinary sodium is doubtless the result of a commensurate fall in urea excretion secondary to the reduced filtration rate. 
tubular reabsorption of sodium might be inhibited throughout the entire length of the nephron or in a specific portion of the nephron, or tubular reabsorptive activity might not be diminished at all, but rather the filtered load of sodium might be increased in a population of nephrons whose sodium reabsorptive capacity remains constant, while at the same time other nephrons which are closing account for the reduced GFR. According to this last hypothesis, the increased excretion of sodium would be caused by the escape of sodium from hyperperfused nephrons rather than by any specific inhibition of tubular reabsorption. Bradley and Wheeler (17) have proposed a similar mechanism in explaining the marked antinatriuresis associated with abdominal compression. In that instance, however, they proposed that well-perfused nephrons dropped out, leaving underperfused nephrons that were quite capable of reabsorbing almost completely their small filtered load of sodium. The studies of de Wardener and associates (11) and Levinsky and Lalone (12), however, did not permit any assessment of these various possibilities.

Our experiments, having been performed during water diuresis, permit a more detailed analysis of the mechanisms responsible for the natriuresis following volume expansion. According to current concepts, the reabsorption of sodium in the proximal tubule is associated with the isosmotic reabsorption of water, whereas in the distal nephron, during water diuresis, sodium reabsorption is independent of water reabsorption and results in the formation of solute-free water (18). Since water reabsorption in the more distal portions of the nephron is minimal during maximal suppression of $\mathrm{ADH}$ activity, the following statements may be made: first, the final urine volume is a rough approximation of the volume of fluid issuing from the more proximal portions of the nephron; second, the percentage of glomerular filtrate reabsorbed in the proximal nephron can be calculated by the expression [GFR - (urine flow/GFR)] $\times 100$; third, $\mathrm{C}_{\mathbf{H}_{2} \mathrm{O}}$ and potassium excretion are a rough index of the amount of sodium reabsorbed in the distal nephron. Therefore, if expansion of ECF volume selectively inhibits sodium reabsorption in the distal nephron, the increased sodium excretion should be associated with a proportionate drop in $\mathrm{C}_{\mathrm{H}_{2} \mathrm{O}}$ and no increase in urine volume (19). If, on the other hand, there is either selective depression of sodium reabsorption in the proximal nephron or hyperperfusion of nephrons, the delivery of isosmotic fluid to the distal nephron should increase, and the ensuing natriuresis should be accompanied by both increased urine flow and increased $\mathrm{C}_{\mathrm{H}_{2} \mathrm{O}}$, as well as a decrease in the calculated fraction of filtrate reabsorbed in the proximal nephron.

In the present experiments the natriuresis after the infusion of hypotonic saline was invariably associated with an increase in urine flow, averaging $+19 \%$ (Table II), and a decrease in the calculated percentage of filtrate reabsorbed in the proximal nephron; an average of about 3\% less filtrate was reabsorbed proximally during the saline diuresis than during water diuresis (last column, Table II). This clearly indicates an increased delivery of isosmotic fluid out of the proximal nephron to the more distal water-impermeable segments. The distal nephron, in contrast, showed no evidence of inhibited sodium reabsorption and, instead, responded normally to the increased delivery of sodium by increasing its rate of free water formation and potassium excretion. The results, therefore, clearly establish that the increased sodium excretion during saline infusion could not be the consequence of an effect in the distal nephron. Rather, the natriuresis must have resulted from accelerated delivery of sodium out of the proximal nephron.

The enhanced delivery of sodium out of the proximal nephron could be due either to selective inhibition of proximal reabsorption or to nephron hyperperfusion. That nephron hyperperfusion is responsible for augmented sodium excretion during aortic constriction seems highly unlikely. If the response to saline infusion is determined solely by nephron hyperperfusion, irrespective of whether the GFR is normal or reduced, then the pattern of solute and water excretion during maximal suppression of $\mathrm{ADH}$ should be similar whether the GFR is either normal or decreased. In the present studies the infusion of hypotonic saline when the GFR was normal resulted in proportionate increases in urine flow, $\mathrm{C}_{\mathrm{H}_{2} \mathrm{O}}$, and $\mathrm{C}_{\mathrm{osm}}$, as well as increased urinary sodium concentration, but no change in urine osmolality ( $U_{\text {osm }}$ ) (Table III). If aortic constriction during hypotonic saline diuresis reduced GFR by causing the closure 
of some nephrons, leaving the remaining patent nephrons hyperperfused, proportionate decreases in urine flow, $\mathrm{C}_{\mathrm{osm}}$, and $\mathrm{C}_{\mathrm{H}_{2} \mathrm{O}}$, but no change in urinary sodium concentration or $\mathrm{U}_{\mathrm{osm}}$, should result. This is, however, not the case (Table III). Aortic constriction during hypotonic saline diuresis actually resulted in a striking decrease in the urinary concentration of sodium and total solutes; and although $\mathrm{C}_{\mathrm{osm}}$ returned to the control values obtained during water diuresis alone, $\mathrm{C}_{\mathbf{H}_{2} \mathrm{O}}$ and urine flow were decreased to a lesser extent, remaining above control values. Since the fall in the urinary concentration of sodium and total solutes is inconsistent with closure of nephrons, it follows that aortic constriction reduces GFR by decreasing the perfusion of all nephrons.

Furthermore, hemodynamic studies provide no evidence of hyperperfusion, inasmuch as Thompson, Barrett, and Pitts (20) have shown that acute reductions in GFR by aortic constriction comparable in degree to those attained in our studies were associated with no significant changes in the maximal rate of tubular glucose transport. Their results also suggest that the decreased GFR was not the consequence of closing off nephrons, but rather of nephron hypoperfusion. From the behavior of $\mathrm{C}_{\mathrm{H}_{2} \mathrm{O}}$ as well as the hemodynamic data, nephron hyperperfusion apparently cannot be invoked to explain saline diuresis during aortic constriction. The logical conclusion is, therefore, that the natriuresis is due to specific inhibition of sodium reabsorption in the proximal nephron.

This decrease in sodium reabsorption in the proximal portions of the nephron, in response to expansion of ECF volume, could occur in either the proximal tubule (pars convoluta and pars recta) by some mechanism that inhibits the active reabsorption of sodium, or in the thin limb of Henle by some alteration in the physical forces that might influence the passive reabsorption of sodium from this area. Recently, Lassiter, Gottschalk, and Mylle (21) demonstrated that the acute infusion of hypertonic saline increased serum concentration and GFR but did not change the percentage of sodium reabsorbed in the proximal convoluted tubule. Similar results have been reported by Giebisch, Klose, and Windhager (22). If these results in rats with elevated GFR can be validly extrapolated to our dogs with reduced GFR, then the percentage of filtered sodium re- absorbed in the proximal convolution should be unchanged by a combination of saline diuresis plus aortic constriction. The present experiments, however, establish that the percentage of filtered sodium reabsorbed in the proximal nephron was reduced (last column, Table II). Therefore, if the demonstration is valid that volume expansion by hypertonic saline does not diminish the fraction of filtrate reabsorbed in the proximal convoluted tubule $(21,22)$, the inhibition of sodium reabsorption must have occurred further along the nephron, either in the pars recta or in the thin limb of Henle.

There are serious reservations, however, to this line of reasoning. When the demonstration that the proximal convolution reabsorbs a constant fraction of the filtered sodium was made, the serum sodium concentration, GFR, and ECF volume were all simultaneously increased. The effects of changes in volume have not been studied when the filtration rate and serum sodium concentration were kept constant. Moreover, the effect of a reduced GFR on the relation between filtered and reabsorbed sodium has not been examined. In our experiments expansion of ECF volume might conceivably in some manner depress sodium reabsorption in the proximal convolution so that the relation between filtered sodium and reabsorbed sodium is altered. Finally, since the depression in the percentage of sodium reabsorption in the proximal tubule required to produce our results is rather small (of the order of 3 to $4 \%$ ), there may be a variation in the fraction of sodium that is reabsorbed in the proximal convolution as ECF volume is varied, which cannot be seen in the usual scattering of results obtained from micropuncture studies. For these reasons the proximal convolution as the site of depressed sodium reabsorption cannot be discounted. The data establish only that volume expansion results in a depression in sodium reabsorption somewhere proximal to the water-impermeable segments of the nephron.

Although a number of factors have been implicated as responsible for the inhibition of tubular reabsorption of sodium following acute saline loading, none has definitely been identified. The decrease in tubular reabsorption is clearly not related to alterations in adrenocortical activity since in the present studies, in those of de Wardener 
and associates (11), and in those of Levinsky and Lalone (12) excess amounts of either aldosterone or $9 \boldsymbol{\alpha}$-fluorohydrocortisone were administered. Changes in endogenous ADH activity, which have been shown by Clapp, Watson, and Berliner (23) to influence sodium reabsorption in the proximal tubule, were obviated in the studies of de Wardener and co-workers (11) and Levinsky and Lalone (12) by an infusion of vasopressin throughout the saline diuresis; in the present studies the influence of $\mathrm{ADH}$ was negligible, since the experiments were performed during maximal water diuresis. Thus, changes in urinary sodium excretion during saline diuresis appear to be independent of changes in the activity of both aldosterone and $\mathrm{ADH}$. A third factor implicated in the inhibition of tubular reabsorption of sodium is a decrease in plasma colloid osmotic pressure secondary to dilution of the plasma proteins by the saline infusion. Although other investigators $(24,25)$ have found that infusion of isoncotic albumin in saline failed to induce natriuresis, Mills, de Wardener, Hayter, and Clapham (26) and Levinsky and Lalone (12) were unable to prevent the saline diuresis by expanding the ECF volume with saline containing isoncotic amounts of albumin. Another possibility is that infusions of isotonic saline, by increasing the chloride-bicarbonate ratio in glomerular filtrate, exceed the relative tubular reabsorptive capacity for $\mathrm{NaCl}$, resulting in augmented excretion of sodium and chloride. This possibility has been excluded, however, by Levinsky and Lalone (12), who expanded volume with Ringer's lactate and thus did not alter the chloridebicarbonate ratio, yet obtained the same degree of natriuresis as when volume was expanded with isotonic saline. Finally, de Wardener and coworkers (11) postulated that a hormonal factor, other than aldosterone, was responsible for the increase in the excretion of sodium following expansion of ECF volume. The results of crosscirculation experiments upon which such a conclusion was based were not, however, entirely convincing because of the consistent increase in the GFR in the recipient dogs.

Thus, while ruling out a number of factors that might be responsible for increased sodium excretion after acute ECF volume expansion with saline, the various studies do not provide information as to the mechanism responsible for this enhanced ability of the kidney to excrete salt. Our studies, however, do suggest that the site at which sodium reabsorption responds to changes in the volume of $\mathrm{ECF}$ is located in the more proximal portions of the nephron.

\section{Summary}

The effect of acute expansion of extracellular fluid volume by hypotonic saline on the excretion of sodium, potassium, and water was examined during water diuresis in 6 dogs. Change in salt and water excretion due to suppression of endogenous adrenocortical activity was avoided by giving large doses of aldosterone to 4 of the dogs. In each experiment glomerular filtration rate was reduced during the saline infusion by constricting the aorta. Despite marked reductions in the filtered load of sodium, the infusion of saline resulted in significant increases in the excretion of sodium, potassium, and solute-free water. We conclude that the natriuresis following acute expansion of extracellular fluid volume with saline is due to specific inhibition of sodium reabsorption in the proximal portions of the nephron by some mechanism independent of the adrenal cortex.

\section{References}

1. Wesson, L. G., Jr. Glomerular and tubular factors in the renal excretion of sodium chloride. Medicine (Baltimore) 1957, 36, 281.

2. Kruhoffer, $P$. The alkali metal ions in biology. IV. Handling of alkali metal ions by the kidney. Handbuch der Exp. Pharmakol. 1960, 13, 233.

3. Goldsmith, C., F. C. Rector, Jr., and D. W. Seldin. Evidence for a direct effect of serum sodium concentration on sodium reabsorption. J. clin. Invest. 1962, 41, 850.

4. Blythe, W. B., and L. G. Welt. Dissociation between filtered load of sodium and its rate of excretion in the urine. J. clin. Invest. 1963, 42, 1491.

5. Burnett, C. H., D. W. Seldin, and M. Walser. Observations on the electrolyte and water metabolism in Addison's disease during oral salt loading. Trans. Ass. Amer. Phycns 1953, 66, 65.

6. Rosenbaum, J. D., S. Papper, and M. M. Ashley. Variations in renal excretion of sodium independent of change in adrenocortical hormone dosage in patients with Addison's disease. J. clin. Endocr. 1955, 15, 1459.

7. Papper, S., L. Saxon, J. D. Rosenbaum, and H. W. Cohen. The effects of isotonic and hypertonic salt solutions on the renal excretion of sodium. J. Lab. clin. Med. 1956, 47, 776.

8. Lombardo, T. A., S. Eisenberg, B. B. Oliver, W. N. Viar, E. E. Eddleman, Jr., and T. R. Harrison. 
Effects of bleeding on electrolyte excretion and on glomerular filtration Circulation 1951, 3, 260.

9. Strauss, M. B. Body Water in Man, 1st ed. Boston, Little, Brown, 1957.

10. Berliner, R. W. Renal excretion of water, sodium, chloride, potassium, calcium, and magnesium. Amer. J. Med. 1950, 9, 541.

11. De Wardener, H. E., I. H. Mills, W. F. Clapham, and C. J. Hayter. Studies on the efferent mechanism of the sodium diuresis which follows the administration of intravenous saline in the dog. Clin. Sci. 1961, 21, 249.

12. Levinsky, N. G., and R. C. Lalone. The mechanism of sodium diuresis after saline loading: evidence for a factor other than increased filtered sodium and decreased aldosterone (abstract). J. clin. Invest. 1963, 42, 951.

13. Walser, M., D. G. Davidson, and J. Orloff. The renal clearance of alkali-stable inulin. J. clin. Invest. 1955, 34, 1520.

14. Snedecor, G. W. Statistical Methods, 5th ed. Ames, Iowa, Iowa State College Press, 1956.

15. Del Greco, F., and H. E. de Wardener. The effect on urine osmolarity of a transient reduction in glomerular filtration rate and solute output during 'water' diuresis. J. Physiol. 1956, 131, 307.

16. Van Giesen, G., M. Reese, F. Kiil, F. C. Rector, Jr., and D. W. Seldin. Unpublished observations.

17. Bradley, S. E., and H. O. Wheeler. On the diversities of structure, perfusion and function of the nephron population. Amer. J. Med. 1958, 24, 692.

18. Smith, H. W. The fate of sodium and water in the renal tubules. Bull. N. Y. Acad. Med. 1959, 35, 293.
19. Sonnenblick, E. H., P. J. Cannon, and J. H. Laragh. The nature of the action of intravenous aldosterone: evidence for a role of the hormone in urinary dilution. J. clin. Invest. 1961, 40, 903.

20. Thompson, D. D., M. J. Barrett, and R. F. Pitts. Significance of glomerular perfusion in relation to variability of filtration rate. Amer. J. Physiol. $1951,167,546$.

21. Lassiter, W. E., C. W. Gottschalk, and M. Mylle. Micropuncture study of net transtubular movement of water and urea in rat kidney during saline diuresis. Fed. Proc. 1963, 22, 277.

22. Giebisch, G., R. M. Klose, and E. E. Windhager Micropuncture study of renal tubular transfer of sodium and water in the rat during sodium chloride loading. Fed. Proc. 1962, 21, 432.

23. Clapp, J. R., J. F. Watson, and R. W. Berliner. Osmolality bicarbonate concentration, and water reabsorption in proximal tubule of the dog nephron. Amer. J. Physiol. 1963, 205, 273.

24. Welt, L. G., and J. Orloff. The effects of an increase in plasma volume on the metabolism and excretion of water and electrolytes by normal subjects. J. clin. Invest. 1951, 30, 751.

25. Strauss, M. B., R. K. Davis, J. D. Rosenbaum, and E. C. Rossmeisl. Production of increased renal sodium excretion by the hypotonic expansion of extracellular fluid volume in recumbent subjects. J. clin. Invest. 1952, 31, 80.

26. Mills, I. H., H. E. de Wardener, C. J. Hayter, and W. F. Clapham. Studies on the afferent mechanism of the sodium chloride diuresis which follows intravenous saline in the dog. Clin. Sci. 1961, 21, 259.

\section{SPECIAL NOTICE TO SUBSCRIBERS}

Post Offices will no longer forward the Journal when you move.

Please notify The Journal of Clinical Investigation, Business Office, 10 Stoughton Street, Boston 18, Mass., at once when you have a change of address, and do not omit the $\mathrm{Zip}$ Code number if there is one. 